\title{
Erratum to: Domestic Supply, Job-Specialization and Sex-differences in Pay
}

\author{
Javier G. Polavieja
}

Published online: 10 October 2009

(C) Springer Science+Business Media B.V. 2009

\section{Erratum to: Soc Indic Res (2009) 93:587-605 DOI 10.1007/s11205-008-9430-5}

Due to technical reasons, the words have been merged without spacing in the second paragraph of the Introduction section. The line should read:

Many sociological and economic factors are surely involved in the processes linking individuals to jobs and jobs to rewards (see Polavieja 2008a). In this paper I will not review all these possible factors at length but propose instead a simple theoretical model that focuses on incentives structures and assumes common rationality across the sexes. In so doing, the model seeks theoretical efficiency in the belief that efficient models can better unearth the structural nature of gender inequalities-i.e. the inequality component that does not depend on differences in actors' attitudes but on the very structure of economic incentives.

The online version of the original article can be found under doi:10.1007/s11205-008-9430-5.

\section{J. G. Polavieja}

Catalan Institution for Research and Advanced Studies (ICREA) \& Institute for Economic Analysis (IAE-CSIC), Barcelona, Spain

J. G. Polavieja $(\bowtie)$

Institute for Economic Analysis (IAE-CSIC), Campus UAB, 08193 Bellaterra, Barcelona, Spain e-mail: javier.polavieja@iae.csic.es 